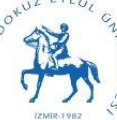

ISSN:1308-8173

Geliş Tarihi: 07.04.2021
İzmir İktisat Dergisi İzmir Journal of Economics

E-ISSN: 1308-8505 YIL: 2022

Kabul Tarihi: 14.12.2021 Online Yayın: 02.03.2022

ÖZGÜN ARAŞTIRMA
Cilt: 37 Sayı: 1 Sayfa: $189-205$

Doi: $10.24988 /$ ije.910996

\title{
Varlık Fiyatlarında Spekülatif Fiyat Baloncuklarının Sağ Kuyruklu ADF Yöntemiyle Analizi
}

Mert URAL 1

\section{Özet}

Bu çalışmanın temel amacl, ekonomik göstergeler üzerinde önemli etkiye sahip olan ve son dönemde üzerlerinde çokça durulan çeșitli varlık fiyatlarında fiyat baloncuklarını araștırmaktır. Bu kapsamda emtia olarak Brent ham petrol (XBR), kıymetli maden olarak altın (XAU) ile hisse senedi olarak GameStop Corp (GME) fiyatlarında baloncukların varlığın GSADF sınamalarıyla araştırmak, ayrıca fiyat baloncuğu başlangıç ve bitiș tarihlerini belirlemek hedeflenmiştir. Bu amaçla, fiyat baloncuklarının varlığı ve gelişme dönemleri Phillips, Shi ve Yu (2015) tarafindan geliştirilen özyinelemeli bir Sağ Kuyruklu (Right Tailed) Genelleștirilmiș Supremum Artırılmıș Dickey Fuller Testi (GSADF) tahminlenerek belirlenmiștir. Calıșmada 02.01.2020-27.10.2021 tarihleri arasindaki USD bazlı olarak Brent ham petrol (XBR), Altın (XAU) ve Game Stop Corp (GME) hisse senedi günlük kapanış fiyatları kullanılmıştır. Elde edilen ampirik bulgular doğrultusunda Altın (XAU) fiyatlarında sadece 21.07.2020-11.08.2020 döneminde fiyat baloncuğu olduğu tespit edilmiştir. Analiz dönemi itibarlyla Brent Petrol (XBR) fiyatlarında özellikle her yıl Mart ayında bir fiyat baloncuğu oluştuğu gözlenmiştir. GameStop Corp (GME) hisse senedi fiyatlarında Ocak 2021 itibarıyla yaşanan spekülatif fiyat baloncuğunun en uzun süren ve en şiddetlisi olduğu anlaşılmıştır. Analize konu edilen varlık fiyatlarında oluşan fiyat baloncukları için ortak bir tarih ve/veya tarih aralığı söz konusu değildir. Anahtar kelimeler: Fiyat baloncukları, RTADF, GSADF

JEL kodu: C58, G10, E60

\section{Analysis of Speculative Price Bubbles in Asset Prices Using the Right-Tailed ADF Method}

\section{Abstract}

The main purpose of this study is to investigate price bubbles in various asset prices, which have a significant impact on economic indicators and have been frequently emphasized recently. In this context, the paper aims to investigate the presence of price bubbles in Brent crude oil (XBR) as commodity, Gold (XAU) as precious metal and GameStop Corp. (GME) as stock prices with GSADF tests, as well as to determine date stamps of the price bubbles. For this purpose, the existence and development periods of price bubbles were determined by estimating a recursive Right Tailed Generalized Supremum Augmented Dickey Fuller Test (GSADF) developed by Phillips, Shi and Yu (2015). Daily closing prices of Brent crude oil (XBR), Gold (XAU) and Game Stop Corp (GME) stocks on USD basis between 02.01.2020-27.10.2021 were used in the study. In line with the empirical findings obtained, it has been determined that there is a price bubble in Gold (XAU) prices only in the period of 21.07.2020-11.08.2020. As of the analysis period, a price bubble has been observed in Brent Oil (XBR) prices, especially in March every year. It has been understood that the speculative price bubble in GameStop Corp (GME) stock prices as of January 2021 is the longest and most severe. There is no common date and/or date range for the price bubbles in the asset prices subject to the analysis.

Keywords: Price bubbles, RTADF, GSADF

JEL Codes: C58, G10, E60

ATIF ÖNERISİ (APA): Ural, M. (2022). Varlık fiyatlarında spekülatif fiyat baloncuklarının sağ kuyruklu ADF yöntemiyle analizi. İzmir İktisat Dergisi. 37(1). 189-205. Doi: 10.24988/ije.910996

1 Prof. Dr., Dokuz Eylül Üniversitesi, İktisadi ve İdari Bilimler Fakültesi, Buca / İZMİR, EMAIL: mert.ural@deu.edu.tr ORCID: 0000-0003-3252-846X 


\section{GİRIŞ}

Finansal varlık fiyatlarında meydana gelen aşırı fiyat şişkinliklerinin oluşturduğu baloncuklar ve ilerleyen dönemlerde söz konusu baloncukların patlaması ekonomik istikrarı tehdit etmektedir (Afşar ve Doğan, 2019:447). Nitekim en son 2008 küresel krizi tecrübesinde görüldüğü üzere baloncukların patlaması sonucu yaşanan finansal çöküşler, bunların ticaret ve/veya sermaye hareketleri yoluyla bulaşıcı etkileri ve nihayetinde bulaşmayı önlemek için oluşturulan büyük hacimli kurtarma paketleri bunun en ciddi göstergesidir (Ahmed, Rosser ve Uppal, 2016). Bu nedenle, varlık fiyatlarında balonlaşma davranışlarının ve zaman içindeki sıklığının araştırılması başta gelişen piyasalar olmak üzere küresel ekonomik istikrar açısından büyük önem arz etmektedir.

Varlık fiyatlarındaki hızlı ve sürekli artışlar, rasyonel kabul edilmeyen bir fiyat baloncuğu olduğunu düşündürmektedir. Fiyat baloncuğu piyasada gerçekleşen değerin hızla artarak temel değerden uzaklaşması durumu olarak ifade edilmektedir (Ghosh, 2016; Hepkorucu ve Genç, 2019: 45; İskenderoğlu ve Akdağ, 2019: 1085; Diba ve Grossman, 1988: 520-530). Bu iki değerin birbirine eşit olmaması risk ve belirsizliğin de giderek arttığı anlamına gelmektedir (Hu ve Oxley, 2017: 420). Fiyat baloncukları tipik olarak reel veya finansal varlık fiyatlarındaki hızlı artışlar ve bunun ardından bir çöküş ile ilişkilendirilmektedir (Malkiel, 2010: 13). Fiyat baloncukları, yatırımcıların "sürü psikolojisi" temelinde yeni alıcllar da eklenerek kendi kendini besleyen (self-sustaining) bir döngü oluşturmaktadır.

Varlık fiyat baloncuklarını talep yanlı şoklar etkilemektedir. Bir süre sonra yatırımcılar, varlık fiyatlarının en üst seviyeye ulaştığını düşünerek portföylerindeki varlıkları satmaya başlamaktadır. $\mathrm{Bu}$ defa ters yönde işleyen sürü psikolojisi sonucu varlık fiyatları dramatik bir şekilde hızla düşmektedir (Büyükduman, 2014: 83-84; Kansu, 2011: 22-26; Lind, 2009: 80). Bu süreç, fiyat baloncuğunun oluşması, büyümesi ve sonunda patlamasını ifade etmektedir.

Varlıkların fiyatlarında meydana gelen baloncukları tespit etmek amacıyla geleneksel olarak varyans testleri, durağanlık testleri, birim kök ve eşbütünleşme testleri yanında Chow ve CUSUM testleri önerilmektedir. Bununla birlikte son dönemde Phillips, Wu ve Yu (2011) ile Phillips Shi ve Yu (2015) çalışmalarında geliştirilen, SADF (Sup-Augmented Dickey-Fuller) ile GSADF (Generalized SupAugmented Dickey-Fuller) testleri fiyat baloncuklarının tespitinde yaygın olarak kullanılmaya başlanmıştır.

Fiyat baloncuğu dönemleri, varlık piyasası verilerinin değişen frekansları için Phillips, Shi ve Yu (2015) çalışmasında geliştirilen özyinelemeli bir sağ kuyruklu Genelleştirilmiş Supremum Artırılmış Dickey Fuller Testi (Generalized Sup-Augmented Dickey Fuller - GSADF) tahminlenerek belirlenmektedir. Özyinelemeli GSADF testi; zaman serisini başlangıçtan sona doğru tek bir düzeyde inceleyen ve benzer şekilde sağ kuyruklu dağılımları dikkate alan yöntemlerden daha detaylı incelemekte ve dolayısıyla daha fazla bilgi içermektedir. Bu durum, tüm zaman serisinde çoklu fiyat baloncuk yapısının incelenmesine olanak sunmaktadır (Hepkorucu ve Genç, 2020: 47). GSADF yöntemi hem fiyat baloncuklarının varlığını hem de bir baloncuğun başlangıç ve bitiş noktalarını yakalayan bir tarih belirleme (datestamping) stratejisine sahiptir (Phillips, Wu ve Yu, 2011: 212).

Bu çalışmanın temel amacl, ekonomik göstergeler üzerinde önemli etkiye sahip olan ve son dönemde üzerlerinde çokça durulan çeşitli varlık fiyatlarında fiyat baloncuklarını araştırmaktır. Bu kapsamda emtia olarak Brent ham petrol (XBR), kıymetli maden olarak Altın (XAU) ile son zamanlarda gündeme giren ve spekülatif hareketler içerdiği kabul edilen GameStop Corp (GME) hisse senedi fiyatlarında baloncukların varlığını GSADF sınamalarıyla araştırmak, ayrıca fiyat balonu başlangıç ve bitiş tarihlerini belirlemek hedeflenmiștir. Melvin Capital isimli hedge fon, Covid-19 salgın sürecinde online satışlardaki artış sonucu, perakende oyun ve oyun konsolu satan GameStop şirketinin değerinin ve hisse senedi fiyatlarının düşeceği beklentisiyle Game Stop hisselerinde kısa pozisyon (short position) almaya başlamıştır. Küçük yatırımcılar ise, bunun GameStop'u batırmak için bir 
operasyon olduğunu düşünerek, rasyonellikten uzak tamamen duygusal biçimde alıma (uzun pozisyon - long position) geçip GameStop hisse senetleri fiyatının yaklaşık 20 katına çımasına neden olmuştur. Kısa pozisyonunu, geri satın alarak kapatmak zorunda kalan Hedge fon, hisseyi açığa sattığı seviyenin çok üstündeki bir fiyattan geri almak zorunda kalmış ve ciddi zarar etmiştir. GameStop hisse senetleri fiyatı halka arz edildiği Şubat 2002'de 10,00 USD civarında iken, Kasım 2007'de 59,24 USD ile en yüksek seviyesinden sonra 2020 yılını 15,15 USD seviyesinden kapatmıștır. Ancak Ocak 2021 itibarıyla hızlı yükseliş trendine giren hisse senedi Şubat ayında tekrar değer kaybetmesine karşın Mart ayı itibarıyla 300,00 USD seviyesine yakın işlem görmeye başlamıştır. Bu hareketler özellikle 2021 yılının ilk üç ayı itibarıyla spekülatif bir fiyat baloncuğuna işaret etmektedir.

$\mathrm{Bu}$ bağlamda, emtia olarak Brent ham petrol (XBR) fiyatlarının seçilme gerekçesi ekonomiler açısından üretimi etkileyen önemli bir maliyet ve dolayısıyla enflasyon unsuru olmasıdır. Kıymetli maden olarak Altın (XAU) fiyatlarının seçilme gerekçesi merkez bankaları tarafından görece az da olsa önemli bir uluslararası rezerv kaynağı olmasıdır. Nitekim altın fiyatlarının arz ve talep yanında ekonomik, sosyal ve politik belirsizlikler ile savașlardan da etkileniyor olması spekülatif fiyat baloncukları için zemin oluşturmaktadır. GameStop Corp olayı, sosyal medya platformu Reddit ortamında bir araya gelen küçük yatırımcıların bazı şirketlerin hisseleri üzerinden profesyonel yatırımcılara karşı başlattığı Wall Street'teki hisse mücadelesi olarak borsa tarihinde önemli bir yer edinmiştir. Dünya borsalarında pek çok hisse senedi işlem görmesine karşın yarattığı önemli etki nedeniyle bu çalışmada GameStop Corp (GME) hisse senedi fiyatlarında fiyat baloncuklarının varlığı analiz edilmiștir. Nitekim tarihi bir manipülasyon olması, sosyal medyanın gücünü göstermesi, Beyaz Saray'ın dahi bu harekete yönelik açıklama yapmayı gerekli görmesi ve borsada benzer şirketlerin hisse senetlerine yönelik getirilen sınırlamalar başta yatırımcılar olmak üzere, araştırmacılar ve politika yapıcılar açısından da klasik bakış açısını değiştirmiştir.

Çalışmanın ikinci bölümünde literatür incelemesi yapılmış, üçüncü bölümünde veri seti ve yöntem açıklanmıștır. Dördüncü bölümde belirlenen varlıklarda fiyat baloncuklarını tespit etmeye yönelik olarak kullanılan GSADF yönteminin analiz bulguları açıklanmış, beşinci bölümde ise sonuç ve değerlendirme yapılmıştır. Çalışmanın literatüre katkısı, küresel piyasalarda dikkatle takip edilen ve ekonomik göstergeleri ciddi anlamda etkileyen ham petrol ve altın fiyatları yanında, daha önce fiyat baloncuklarına ilişkin henüz bir araştırma yapılmamış olan GameStop Corp hisse senedi fiyatlarının analiz edilmiş olmasıdır.

\section{LITERATÜR TARAMASI}

Literatürde hisse senedi, döviz, emtia, kıymetli maden piyasalarında, kripto para piyasalarında ve konut piyasalarındaki fiyat baloncuklarının varlığını araştırmış birçok çalışma yer almaktadır. Fiyat baloncuklarının belirlenmesi için çeşitli metodolojiler kullanılmakla birlikte, çoklu fiyat baloncuklarının belirlenmesinde son yıllarda Phillips, Shi ve Yu'nun 2015 yılında kullandığı GSADF testi ön plana çıkmıştır. Phillips, Shi ve Yu (2015) tarafından geliştirilen GSADF testini kullanan bazı çalışmalar aşağıdaki gibi gruplandırılarak sıralanmıştır:

Hisse senedi, döviz, emtia ve kıymetli maden piyasalarındaki fiyat baloncuklarını belirlemek üzere yine GSADF testini kullanan bazı çalışmalar: Bettendorf ve Chen (2013), Jiang, Wang, Chang ve Su (2015), Korkmaz, Erer ve Erer (2016), Hu ve Oxley (2017),Pavlidis, Paya ve Peel (2017), Rasekhi, Elmi ve Shahrazi (2017), Akkaya (2018), Çelik, Akkuş ve Gülcan (2019), Kılıç (2020), Gülcan, Boyacıoğlu ve Özdemir (2021) olarak belirtilebilir. Bu çalışmada da GSADF testi ile çeşitli finansal varlık fiyatlarındaki spekülatif baloncuklar araştırıldığından özellikle bu gruptaki çalışma bulguları detaylandırılmıştır. $\mathrm{Bu}$ çalışmalar arasında sadece tek tip finansal varlıklar seçilerek analizler yapıldığı görülmüş, varlık çeşitlendirmesi yaparak analiz gerçekleştiren bir çalışmaya rastlanmamıştır. Bu durum, çalışmanın bir diğer katkısı olarak vurgulanabilir. 
Bettendorf ve Chen (2013), 1972:01-2012:06 dönemi için 486 aylık veri üzerinden yaptıkları analizde nominal GBPUSD döviz kurunda patlayıcı davranıș sergileyen bir fiyat baloncuğu tespit etmişlerdir. Jiang, Wang, Chang ve Su (2015), 1995:07-2013:10 dönemi için yaptıkları analizde nominal USDRMB döviz kurunda 2005-2006 dönemi ve 2008 küresel finans krizi döneminde patlayıcı davranış sergileyen iki fiyat baloncuğu bulmuşlardır. Korkmaz, Erer ve Erer (2016), 2002:01-2016:05 dönemi için alternatif yatırım araçlarında ortaya çıkan fiyat baloncuklarının Borsa İstanbul 100 (BIST 100) endeks getirisi oynaklığı üzerindeki etkisi incelenmişler ve çalışmanın sonucunda, altın fiyatları ile USDTRY döviz kurunda meydana gelen artışların BIST 100 endeksi oynaklığını arttırdı ̆̆ı, bununla birlikte altın fiyatlarındaki balonların BIST 100 endeks oynaklığını azalttığı bulgularına ulaşmışlardır. Hu ve Oxley (2017), 1991:03-2014:12 dönemi için G10, Asya ve BRICS ülkeleri üzerine yaptıkları analizde özellikle yeni gelişen piyasalar açısından fiyat baloncuğu gerçekleşme olasılığının daha yüksek olduğu sonucuna ulaşmışlardır. Pavlidis, Paya ve Peel (2017), 24.12.1921 - 11.08.1923 dönemi günlük DEMUSD ve GBPUSD döviz kurları üzerinden gerçekleştirdikleri analizde iki dünya savașı arasında yaşanan Alman hiperenflasyonu sırasında biri Temmuz-Ağustos 1922'de ve diğeri bir yıl sonra 1923 yaz döneminde USD döviz kurunda iki kısa süreli fiyat baloncuğu tespit etmişlerdir. Rasekhi, Elmi ve Shahrazi (2017), 2002:04-2016:03 dönemi için İran döviz piyasasında gerçekleştirdikleri analizde 2008:10-2008:12, 2012:01-2012:03 ve 2013:09-2013:11 arasında nominal döviz kurlarında fiyat baloncukları olduğunu bulgulamışlardır. Akkaya (2018), 2004:03-2004:09, 2004:12-2005:11, 2006:06-2007:06, 2010:02-2010:04, 2010:072010:10 ve 2012:07-2012:10 dönemlerinde Borsa İstanbul getiri endeksinde fiyat baloncukları oluştuğunu belirlemiştir. Çelik, Akkuş ve Gülcan (2019), 01.01.2010-19.02.2019 dönemi için klymetli madenler üzerinde yapılan çalışmada, altın, gümüş ve platin fiyatlarında balona rastlanırken, paladyum fiyatında herhangi bir balonun varlığına dair kanıt bulunamamıștır. Kılıç (2020), BRICS-T (Brezilya, Rusya, Hindistan, Çin, Güney Afrika, Türkiye) ülke borsalarında 1994:12-2020:03 dönemi için yapılan analiz sonuçlarına göre, sadece Çin Borsasında üç farklı dönemde balonların oluşumuna dair kanıtlar elde edilmiştir. Gülcan, Boyacıoğlu ve Özdemir (2021), USD, EUR, GBP ve CNY için 03.01.2005-20.11.2019 dönemi; JPY için de 28.08.2013-20.11.2019 dönemi günlük fiyat verilerini kullandıkları çalıșma sonucunda, Türkiye döviz piyasasında fiyat baloncuklarının oluşumuna yönelik bulgulara ulaşılmıştır.

Kripto para birimlerindeki fiyat baloncuklarını GSADF yöntemiyle araștıran çalışmalar: Cheung, Roca ve Su (2015), Landgraf (2016), Wei (2017), Corbet, Lucey ve Yarovaya (2018), Bouri, Shahzad ve Roubaud (2018), Ceylan, Tüzün, Ekinci ve Kahyaoğlu (2018), Zeren ve Esen (2018), Su, Li, Tao ve Si (2018), Mete, Koy ve Ersoy (2019), Hepkorucu ve Genç (2019), Enoksen, Landsnes, Lučivjanská ve Molnár (2020), Şahin (2020) olarak belirtilebilir.

Konut piyasalarındaki fiyat baloncuklarını GSADF yöntemiyle araştıran çalışmalar ise: Zeren ve Ergüzel (2015), Engsted, Hviid ve Pedersen (2015), Shi, Valadkhani, Smyth ve Vahid (2016), Escobari ve Jafarinejad (2016), Coşkun ve Jadevicius (2017), Afşar ve Doğan (2018), Evrim Mandacı ve Çağlı (2018), Hu ve Oxley (2018), İskenderoğlu ve Akdağ (2019), Gökçe ve Güler (2020), Abioğlu (2020) olarak belirtilebilir. Hem kripto para birimleri hem de konut piyasalarına ilişkin bu çalışmalarda, belirli dönemlerde spekülatif fiyat baloncukları olduğu tespit edilmiştir.

\section{VERI VE METODOLOJİ}

Çalışmada, Brent Petrol (XBR), Altın (XAU) ve GameStop Corp (GME) hisse senedi fiyatlarında 2020 yılından itibaren spekülatif baloncukların varlığı ve balon oluşum tarihleri, Phillips, Shi ve Yu (2015) çalışmasında geliştirilen sağ kuyruklu birim kök testi olan GSADF ile belirlenmeye çalışılmıştır. Çalışmada 02.01.2020-27.10.2021 tarihleri arasındaki USD bazlı olarak XBR, XAU ve GME günlük kapanış fiyatları kullanılmıştır. Veriler investing.com veri tabanından alınmıştır. 
Fiyat baloncuklarının belirlenmesinde kullanılan regresyon modeli aşağıdaki gibi yazılabilir (Phillips, Shi ve Yu, 2015: 1047):

$$
y_{t}=d T^{-\eta}+\theta y_{t-1}+\varepsilon_{t}, \varepsilon_{t} \square^{i i d} N\left(0, \alpha^{2}\right), \theta=1
$$

Burada; $d$ sabit terim, $T$ gözlem sayısı, $\eta$ katsayısı ise sabit ve $T \rightarrow \infty$ giderken kaymanın (drift) büyüklügünü kontrol eden yerelleştirme-sınırlama katsayısıdır. Phillips, Shi ve Yu yaklaşımında boş hipotez $\left(\mathrm{H}_{0}\right)$, varlık fiyatının asimptotik olarak ihmal edilebilir bir kayma ile rassal yürüyüş süreci izlediğini varsaymakta, alternatif hipotez $\left(\mathrm{H}_{1}\right)$ altında $\theta>1$ ise fiyatlarda oluşan balonun varlığını göstermektedir (Ceylan vd., 2018: 266-267). Denklem (1) çözümlendiğinde, $\frac{d t}{T^{\eta}}$ deterministik kaymayı veren aşağıdaki denklem elde edilir:

$$
y_{t}=d \frac{t}{T^{-\eta}}+\sum_{j=1}^{t} \varepsilon_{j}+y_{0}
$$

Burada, $\eta>0$ olduğunda kayma, doğrusal bir trende göre küçüktür. $\eta>1 / 2$ olduğunda kayma, $y_{t}$ 'nin martingal bileşenine göre küçüktür. $\eta<1 / 2$ olduğunda ise, standartlaştırılmış $T^{-\frac{1}{2}} y_{t}$ çıktı, kayma içeren Brownian hareket gibi asimptotik olarak davranır. Çalışmada, $y_{t}$ 'nin büyüklük düzeyinin pür rassal yürüyüşle aynı olduğu $\eta>1 / 2$ durumu ele alınmıştır.

Özyinelemeli yaklaşım, durağanlık testi için kayan pencereli ADF tarzı bir regresyon içerir. Kayan pencereli regresyon toplam örneklemin $(T) r_{1}^{\text {th }}$ kısmından başlar ve $r_{2}^{\text {th }}$ kısmında sona erer. Burada $r_{2}=r_{1}+r_{w}$ ve $r_{w}>0$ regresyonun kismi pencere boyutudur. $H_{0}: H_{0}: \hat{\beta}=1$ ve $H_{1}: \hat{\beta}>1$ olmak üzere, ampirik regresyon modeli şöyle yazılabilir:

$$
\Delta y_{t}=\hat{\alpha}_{r_{1}, r_{2}}+\hat{\beta}_{r_{1}, r_{2}} y_{t-1}+\sum_{i=1}^{k} \hat{\psi}_{r_{1}, r_{2}}^{i} \Delta y_{t-i}+\hat{\varepsilon}_{t}
$$

Burada, k (geçici) gecikme sayısıdır. $T_{w}=\left[\operatorname{Tr}_{w}\right]$ regresyondaki toplam gözlem sayısı olmak üzere [.] tamsayı kısmını gösteren taban fonksiyonudur. Bu regresyona dayalı ADF istatistiği $A D F_{r_{1}}^{r_{2}}$ şeklinde gösterilir. Böylece, özellikle birden fazla baloncuk tespiti için bu tür kayan pencereli regresyon kullanıldığı anlaşılmaktadır. GSADF test istatistiğine ait asimptotik kritik değerler Monte Carlo simülasyonlarıyla belirlenmektedir.

Genelleştirilmiş Dickey Fuller (GSADF) testi, özyinelemeli bir şekilde toplam gözlem sayısının alt örneklemleri üzerinde tekrarlanan ADF testi regresyonlarına dayanmaktadır. Pencere boyutu $\left(r_{w}\right)$ en küçük örneklem penceresi genişliği olan ro'dan en büyük örneklem penceresi genişliği olan ve toplam örneklem boyutunu ifade eden 1'e yayılmaktadır. Örneklemin başlangıç noktası $r_{1}$ olmak üzere 0'da sabitlenmiştir. Her bir örneklemin son noktası $r_{2}$ olmak üzere pencere boyutu $r_{w}$ 'ya eşittir. Örneklem başlangıç noktası $r_{1}$, ródan 1'e doğru değişmektedir. 0'dan $r_{2}^{\prime}$ ye doğru çalışan bir örneklemin ADF istatistiği $A D F_{0}^{r_{2}}$ şeklinde gösterilir (Zeren ve Esen, 2018: 441). Aşağıdaki yer alan Şekil 1, örneklem aralığında kayan pencereler bağlamında GSADF sürecini göstermektedir (Caspi, 2013: 6). 
Şekil 1. GSADF Test Süreci Örneklem Aralığı $[0,1]$

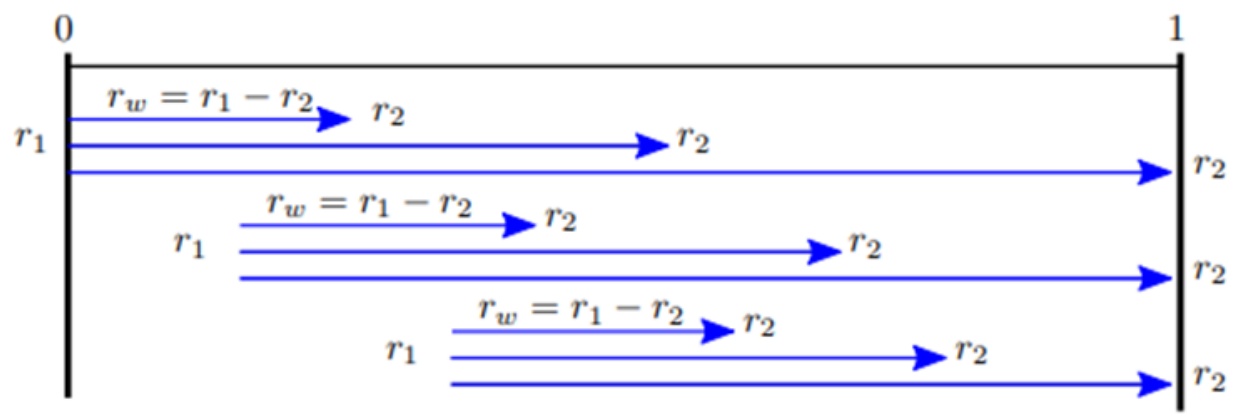

GSADF testinde, örneklemdeki başlangıç noktası sabit olmayıp başlangıç ve bitiş noktaları üzerinde kaydırılmaktadır. Böylece GSADF yöntemiyle çok sayıda baloncuğun tespiti olanaklı hale gelmektedir. GSADF, doğrusal olmayan yapılar ile yapısal kırılmaları da dikkate almaktadır (Çağlı ve Mandacl, 2017: 66).

GSADF test istatistiği, bu çift yinelemede tüm uygulanabilir $r_{1}$ ve $r_{2}$ aralıklarında en büyük ADF istatistiği olarak tanımlanır ve aşağıdaki șekilde GSADF(ro) gösterilir (Phillips, Shi ve Yu: 2015: 1049; Enoksen, Landsnes, Lucivjanská ve Molnár, 2020: 142):

$$
\operatorname{GSADF}\left(r_{0}\right)=\sup _{\substack{r_{2} \in\left[r_{0}, 1\right] \\ r_{1} \in\left[0, r_{2}-r_{0}\right]}}\left\{A D F_{r_{1}}^{r_{2}}\right\}
$$

Regresyon modeli bir sabit terim içerdiğinde ve boş hipotez $\left(\mathrm{H}_{0}\right)$, denklem (1)'de olduğu gibi asimptotik olarak ihmal edilebilir bir kayma değerine (yani, $\eta>1 / 2$ ve d sabit terim olmak üzere $d T^{-\eta}$ ) sahip rassal yürüyüş olduğunda GSADF test istatistiğinin limit dağılımı, $W$ standart bir Wiener süreci ve $r_{w}=r_{2}-r_{1}$ olmak üzere aşağıdaki gibi yazılabilir.

$$
=\sup _{\substack{r_{2} \in\left[r_{\left.r_{1}, 1\right]}, r_{1} \in\left[0, r_{2}-r_{0}\right] \\ r_{1}\right.}}\left\{\frac{\frac{1}{2} r_{w}\left[W\left(r_{2}\right)^{2}-W\left(r_{1}\right)^{2}-r_{w}\right]-\int_{r_{1}}^{r_{2}} W(r) d r\left[W\left(r_{2}\right)-W\left(r_{1}\right)\right]}{r_{w}^{\frac{1}{2}}\left\{r_{w} \int_{r_{1}}^{r_{2}} W(r)^{2} d r-\left[\int_{r_{1}}^{r_{2}} W(r) d r\right]^{2}\right\}^{\frac{1}{2}}}\right\}
$$

Denklem (4) ve dolayısıyla denklem (5) yardımıyla hesaplanan GSADF test istatistikleri, Monte Carlo simülasyonları sonucunda hesaplanan kritik değerlerden büyükse, finansal baloncukların olmadığını iddia eden boş hipotez reddedilir (Çelik, Akkuş ve Gülcan, 2019: 943). Boş hipotezin reddedilmesi, fiyat serilerinde rasyonel baloncukların varlığına işaret etmektedir (Gökçe ve Güler, 2020: 996).

Uygulamada, ro'ın toplam gözlem sayısı $T$ "ye göre seçilmesi gerekir. Eğer $T$ küçükse, başlangıç tahmini için yeterli gözlem olmasını sağlayacak kadar $r o$ 'ın büyük olması gerekir. Eğer $T$ büyükse, $r_{0}$ daha küçük olabilir, böylece GSADF testi erken bir patlama/baloncuk olayını saptayabilir. Kapsamlı simülasyon bulgularına dayanarak minimum pencere boyutunun seçimine yönelik, $r_{0}=0,01+\frac{1,8}{\sqrt{T}}$ şeklinde basit fonksiyonel formda bir kural önerilmektedir. Minimum pencere boyutu ro küçüldükçe, GSADF test istatistiğinin kritik değeri artmaktadır (Phillips, Shi ve Yu, 2015: 1050).

Baloncukların varlığı tespit edildikten sonra, baloncukların oluşum dönemleri geriye dönük SADF (Backwards sup ADF - BSADF) istatistik dizilerinden yararlanılarak belirlenmektedir. BSADF 
istatistik dizileri geriye doğru (backwards) genişleyen yapıdaki örneklemler için sağ kuyruklu ADF testleri uygulanarak elde edilmektedir. BSADF istatistiği ve buna bağlı olarak GSADF istatistiği sırasıyla aşağıdaki gibi yazılabilir (Caspi, 2013: 7):

$$
\begin{aligned}
& \left\{\operatorname{BSADF}_{r_{2}}\left(r_{0}\right)\right\}_{r_{2} \in\left[r_{0}, 1\right]} \\
& \operatorname{GSADF}\left(r_{0}\right)=\sup _{r_{2} \in\left[r_{0}, 1\right]}\left\{B S A D F_{r_{2}}\left(r_{0}\right)\right\}
\end{aligned}
$$

Elde edilen BSADF dizileri Monte Carlo simülasyonuyla hesaplanan sağ kuyruklu kritik değerler dizisiyle karşılaştırılarak balonların oluşum tarihleri belirlenmektedir (Ceylan vd., 2018: 267).

\section{AMPİRIKK BULGULAR}

Çalışmanın ampirik bulguları tablolar ve şekiller yardımıyla sunularak yorumlanmıştır. Brent Petrol (XBR), Altın (XAU) ve GameStop Corp (GME) hisse senedi fiyat serileri için uygun pencere boyutları $r_{0}=0,01+\frac{1,8}{\sqrt{T}}$ formülüyle hesaplanmış ve sırasıyla 45, 44, 43 olarak belirlenmiştir. Nitekim $T$ küçük olduğundan, başlangıç tahmini için yeterli gözlem olmasını sağlayacak kadar ro'ın büyük olması gerektiğini doğrulamaktadır.

Tablo 1'de yer alan tanımlayıcı istatistikler genel olarak değerlendirildiğinde analiz dönemi itibarıyla tüm fiyat serileri için ortalama fiyatlar pozitif bulunmuştur. Bununla birlikte ortalama, en büyük ve en küçük değerler itibarıyla XAU en yüksek olup buna bağlı olarak oynaklık (standart sapma) değeri de en yüksek çıkmıştır. Çarpıklık katsayıları GME için pozitif olup sağ çarpık (right skewed) bir dağılım buna karşın XBR ve XAU için negatif olup sol çarpık (left skewed) bir dağılım söz konusudur. Çarpıklık katsayıları için normal dağılıma ilişskin kritik değer 0'dır ve XAU ile GME fiyat serileri için çarpıklık katsayıları 0'dan oldukça uzaktır. Basıklık katsayıları incelendiğinde, tüm finansal varlık fiyat serileri için normal dağılıma ilişkin kritik değer olan 3'ten küçüktür. Buna göre, fiyat serileri şişman kuyruk (fat tail) özelliğine sahip görülmemektedir. Çarpıklık ve basıklık katsayılarının yüksek olması fiyatlarda baloncuk olasılığını da artırmaktadır. Varlık fiyat serilerinin normallik varsayımını sinayan Jargue-Bera istatistikleri incelendiğinde, XBR, XAU ve GME fiyat serilerinin normal dağılıma uymadıkları anlașılmıştır.

Tablo 1. Tanımlayıcı İstatistikler

\begin{tabular}{cccc}
\hline & $\begin{array}{c}\text { Brent Petrol } \\
\text { (XBR) }\end{array}$ & $\begin{array}{c}\text { Altın } \\
\text { (XAU) }\end{array}$ & $\begin{array}{c}\text { GameStop Corp } \\
\text { (GME) }\end{array}$ \\
\hline Gözlem Sayısı & 504 & 475 & 460 \\
Ortalama & 56,06 & $1.783,42$ & 78,93 \\
En Büyük & 86,28 & $2.063,19$ & 347,51 \\
En Küçük & 18,69 & $1.469,80$ & 2,80 \\
Standart Sapma & 16,40 & 110,75 & 89,63 \\
Çarpıklık & $-0,225997$ & $-0,421404$ & 0,666077 \\
Basıklık & 2,026542 & 2,908999 & 1,875196 \\
\hline Jarque-Bera & 24,19 & 14,22 & 58,26 \\
& $(0,0000)$ & $(0,0008)$ & $(0,0000)$ \\
\hline
\end{tabular}

Not: Parantez içindeki değerler olasılıkları ifade etmektedir.

Aşağıda yer alan Şekil 2, 3 ve 4 sırasıyla Brent Petrol (XBR), Altın (XAU) ve GameStop Corp (GME) fiyat serilerine ait zaman yolu şekillerini göstermektedir. Şekillerdeki dik çizgiler 2021 yılı başlangıcını göstermektedir. Görüleceği üzere, Brent Petrol (XBR) fiyat serisi ilk olarak 22.04.2020'de ardından 30.10.2020'de ikinci yükseliş eğilimine girmiştir. 08.03.2021 ve 
01.08.2021'de kısa süreli düşüşler yaşanmasına karşın Ekim 2021 itibarıyla halen yükselişini sürdürmektedir. Altın (XAU) fiyat serisi 19.03.2020'de yükseliş, 05.08.2020'de ise düşüş eğilimine girmiştir. 31.03.2021'de tekrar yükseliş eğilimi göstermesine karşın Haziran-Ekim 2021 aralığında küçük dalgalanmalar içeren yatay bir seyir izlediği söylenebilir. GameStop Corp (GME) fiyat serisi, Ocak 2021'de yükseliş, Şubat 2021'de düşüş eğilimi göstermiştir. 15.03.2021'e kadar yükselme eğilimine girmesine karşın bu tarihten sonra genel olarak düşüş eğilimi sergilemektedir.

Şekil 2. Brent Petrol (XBR) Kapanış Fiyatları

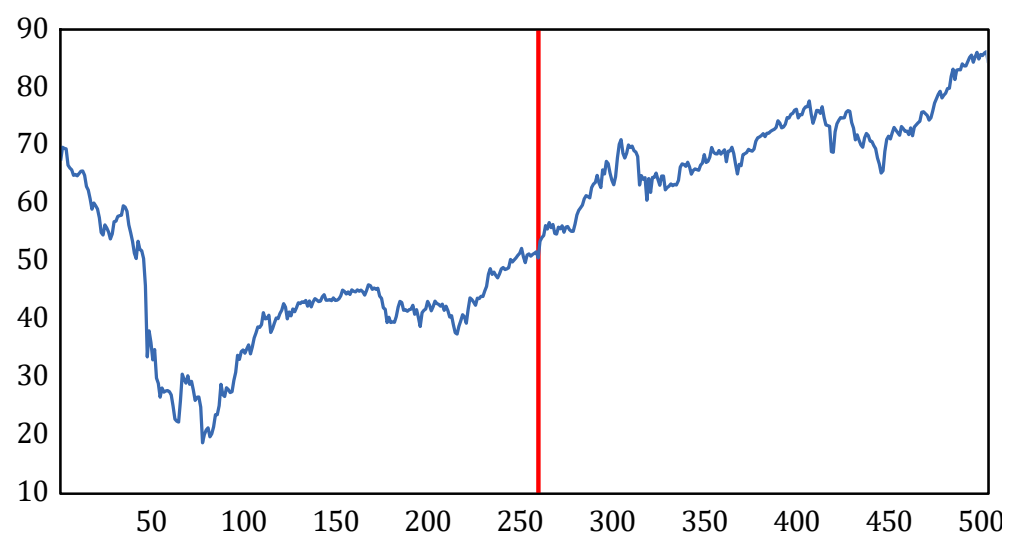

Şekil 3. Altın (XAU) Kapanış Fiyatları

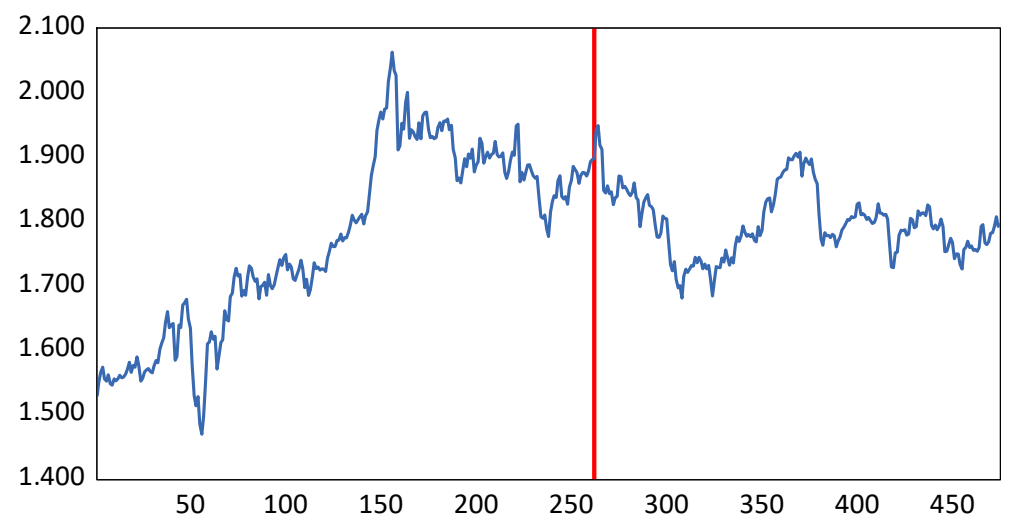

Şekil 4. GameStop Corp (GME) Kapanış Fiyatları

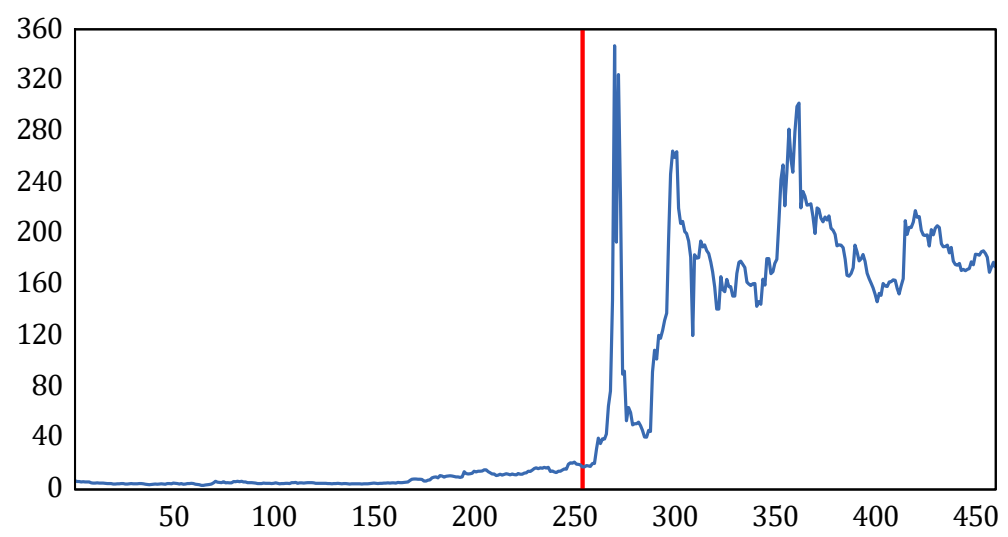


Yine Şekil 1, 2 ve 3 incelendiğinde, Brent Petrol (XBR), Altın (XAU) ve GameStop Corp (GME) fiyat serilerinde farklı dönemlerde yaşanan yükseliş eğilimlerinin bir fiyat baloncuğu olup olmadığı yanında baloncuk başlangıç ve bitiş tarihlerinin belirlenmesi önem arz etmektedir. Bu bağlamda GSADF yöntemi bir “erken uyarı" aracı niteliği sunabilir (Ceylan vd., 2018: 268).

Tablo 2, Brent Petrol (XBR), Altın (XAU) ve GameStop Corp (GME) hisse senedi fiyat serileri için denklem (4) ve denklem (5)'te verilen GSADF test istatistiklerini göstermektedir. Uygun pencere boyutuna göre Monte Carlo simülasyonlarına dayalı olarak 2000 deneme ile kritik değerler elde edilmektedir. Her bir fiyat serisi için yaklaşık binlerce regresyon tahminlenmiştir (Gökçe ve Güler, 2020). Örneğin Brent Petrol (XBN) için (504-45)x2.000=918.000 tane regresyon tahminlenmiştir. Bu kapsamda bir GSADF testi yaklaşık 28 saatlik bir hesaplama sürecinde sonlanmıștır**. Altın (XAU) ve GameStop Corp (GME) hisse senedi fiyat serilerinde \%99 güven düzeyinde Brent Petrol (XBR) fiyat serisi için \%90 güven düzeyinde GSADF test istatistiği kritik değerlerden büyüktür. İstatistiksel olarak 02.01.2020-27.10.2021 dönemi için Brent Petrol (XBR), Altın (XAU) ve GameStop Corp (GME) hisse senedi fiyat serilerinde fiyat baloncukları olduğu anlaşılmıştır.

Tablo 2. GSADF Test İstatistiği Sonuçları

\begin{tabular}{clccc}
\hline Değişken & $\begin{array}{c}\text { GSADF } \\
\text { Test İstatistiği }\end{array}$ & $\begin{array}{c}\text { Pencere } \\
\text { Boyutu }\end{array}$ & $\begin{array}{c}\text { Gecikme } \\
\text { Sayısı }\end{array}$ & $\begin{array}{c}\text { Fiyat } \\
\text { Baloncuğu }\end{array}$ \\
\hline Brent Petrol (XBR) & $2,028583^{* * *}$ & 45 & 0 & VAR \\
Altın (XAU) & $3,208440^{*}$ & 44 & 0 & VAR \\
GameStop Corp (GME) & $23,54784^{*}$ & 43 & 0 & VAR \\
\hline
\end{tabular}

Not: *, **, *** işaretleri hesaplanan GSADF test istatistiğinin sırasıyla \%1, \%5 ve \%10 düzeyinde istatistiksel olarak anlamlı bulunduğunu ifade etmektedir. GSADF test istatistikleri için kritik değerler, \%1, \%5 ve \%10 anlamlılık düzeylerinde XBR için sırasıyla 2,890263, 2,228069, 2,024527; XAU için sırasıyla 2,805384, 2,259173, 2,025534; GME için sırasıyla 2,703558, 2,227768, 2,004786. Kritik değerler gözlem sayıları üzerinden 2000 tekrarlı Monte Carlo simülasyonları ile elde edilmiştir.

Fiyat baloncukları varlığının belirlenmesinden sonra, analiz dönemi boyunca kaç baloncuk oluştuğu ve baloncukların başlangıç-bitiş tarihleri yöntem kısmında açıklandığı üzere BSADF yöntemiyle gözlemlenebilir. BSADF dizisinin kritik değer dizisini yukarı doğru kesmesi fiyat baloncuğunun başlangıç noktasını, aşağı doğru kesmesi ise fiyat baloncuğunun bitiş noktasını gösterir. Ayrıca BSADF dizisinin kritik değer dizisinin üzerinde kalan kısmı ne kadar büyükse, spekülatif fiyat baloncuğunun piyasaya etkisi de o derece yüksek olacaktır.

Şekil 5, 6 ve 7'de sırasıyla Brent Petrol (XBR), Altın (XAU) ve GameStop Corp (GME) hisse senedi fiyat serilerinden tahmin edilen BSADF dizileri, \%95 güven düzeyinde elde edilen kritik değer dizileriyle karşılaştırılmıştır. Spekülatif fiyat baloncuklarının başlangıç ve bitiş tarihleri gölgelendirilerek gösterilmiştir.

** Intel Core i7-10510U CPU @ 1.80GHz - 2.30 GHz, 16 GB ram içeren bilgisayar kullanılmıștır. 
Şekil 5. Brent Petrol (XBR) İçin BSDAF Dizilerine Bağlı Fiyat Baloncukları

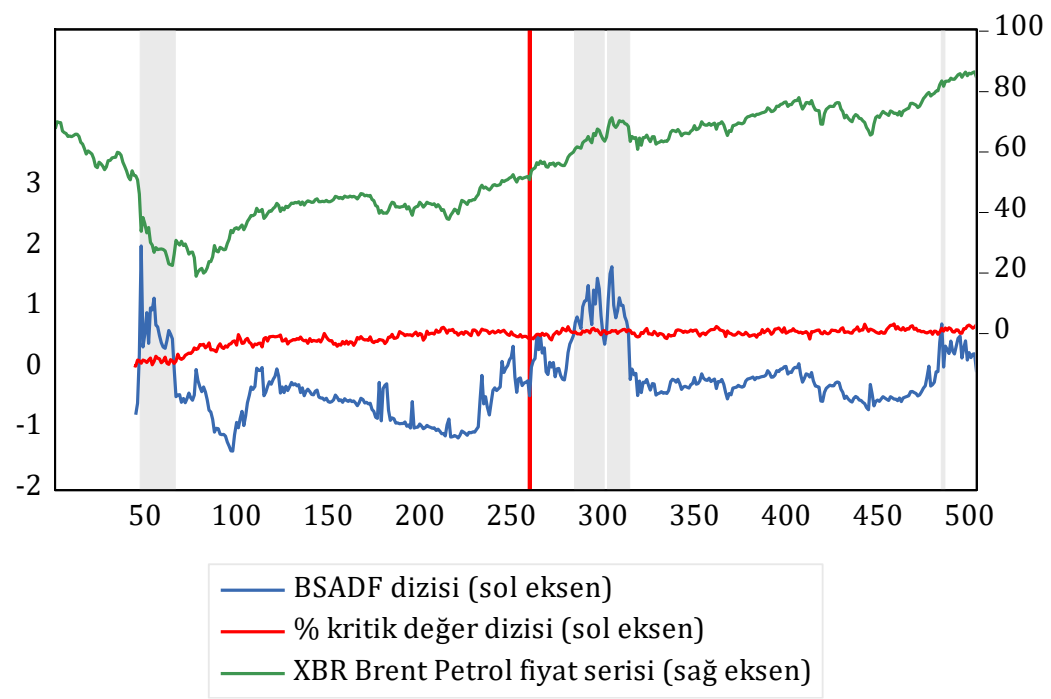

Şekil 6. Altın (XAU) İçin BSDAF Dizilerine Bağlı Fiyat Baloncukları

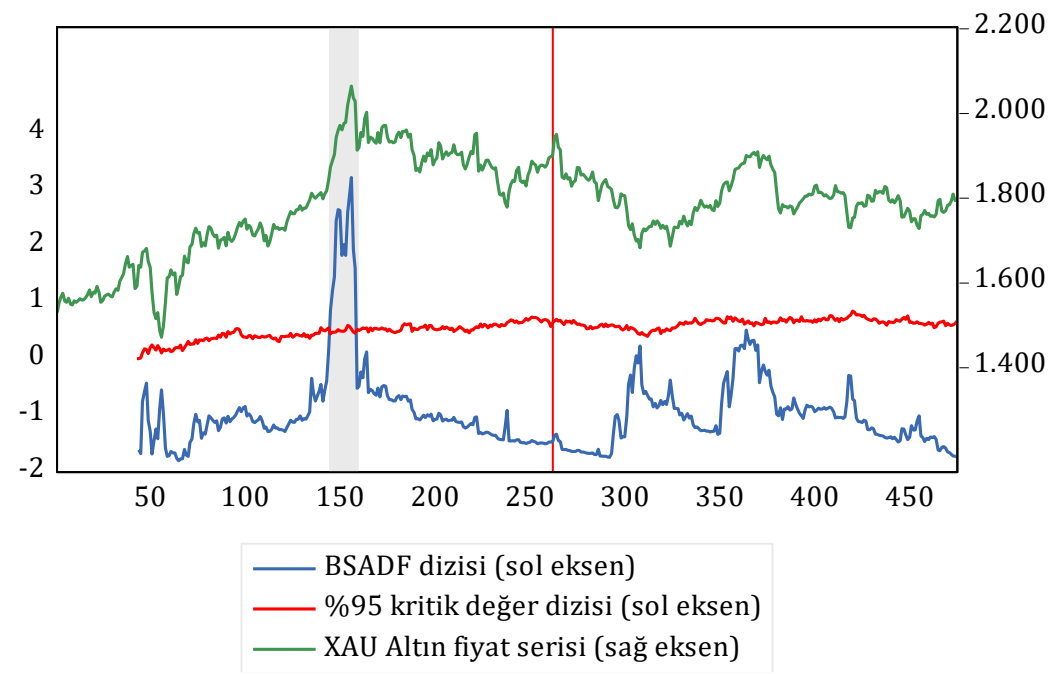

Şekil 7. GameStop Corp (GME) İçin BSDAF Dizilerine Bağlı Fiyat Baloncukları

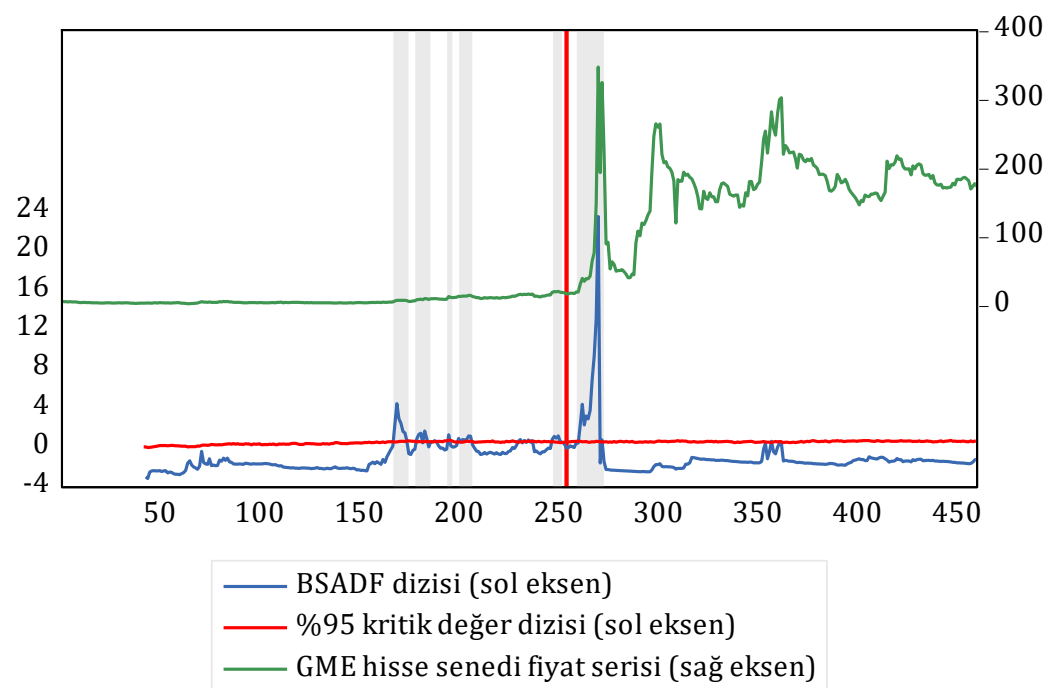


Tablo 3'ten görüleceği üzere Brent Petrol (XBR), Altın (XAU) ve GameStop Corp (GME) hisse senedi fiyatlarında analiz döneminin muhtelif tarih ve tarih aralıklarında fiyat değerleri kritik değer dizilerini aşmıştır. Elde edilen ampirik bulgular Brent Petrol (XBR), Altın (XAU) ve GameStop Corp (GME) hisse senedi fiyatlarında çok sayıda fiyat baloncuğu olduğunu göstermektedir. Bununla birlikte aynı analiz dönemi için en fazla fiyat baloncuklarının GameStop Corp (GME) hisse senedi fiyatlarında ve en uzun süren fiyat baloncuklarının Brent Petrol (XBR) fiyatlarında gerçekleştiği gözlenmiştir. Altın (XAU) fiyatlarında sadece 21.07.2020-11.08.2020 döneminde fiyat baloncuğu olduğu tespit edilmiştir. Brent Petrol (XBR) fiyatlarında Mart 2020, Şubat 2021, Mart 2021 ve Ekim 2021 döneminde fiyat baloncukları görülmüştür. Analiz dönemi itibarıly Brent Petrol (XBR) fiyatlarında özellikle her yıl Mart ayında bir fiyat baloncuğu oluştuğu gözlenmiştir. Burada ilginç olan nokta GameStop Corp (GME) hisse senedi fiyatlarına ilişkindir. Nitekim, GameStop Corp (GME) hisse senedi fiyatlarında tarihi bir manipülasyon hareketi kabul edildiği sadece Ocak 2021'de değil, daha öncesinde Eylül, Ekim ve Aralık 2020 döneminde de fiyat baloncukları oluştuğu tespit edilmiștir. Bununla birlikte, Ocak 2021 itibarıyla yaşanan spekülatif fiyat baloncuğunun en uzun süren ve en şiddetlisi olduğu anlaşılmıştır. Seçilen varlık fiyatlarında oluşan fiyat baloncukları için ortak bir tarih ve/veya tarih aralığı söz konusu değildir.

Tablo 3. Varlık Fiyatlarında Oluşan Fiyat Baloncuğu Tarihleri

\begin{tabular}{|c|c|c|c|}
\hline & XBR & & XAU \\
\hline \multirow{2}{*}{27 gün } & 06.03 .2020 & \multirow{2}{*}{21 gün } & 21.07 .2020 \\
\hline & 02.04 .2020 & & 11.08 .2020 \\
\hline \multirow{2}{*}{24 gün } & 05.02 .2021 & & \\
\hline & 01.03 .2021 & & \\
\hline \multirow{2}{*}{14 gün } & 03.03 .2021 & & \\
\hline & 17.03 .2021 & & \\
\hline \multirow{2}{*}{2 gün } & 04.10 .2021 & & \\
\hline & 06.10 .2021 & & \\
\hline
\end{tabular}

\begin{tabular}{|c|c|}
\cline { 2 - 2 } \multicolumn{1}{c|}{ GME } \\
\hline \multirow{2}{*}{$\mathbf{1 2}$ gün } & 28.08 .2020 \\
\cline { 2 - 2 } & 09.09 .2020 \\
\hline \multirow{2}{*}{$\mathbf{9}$ gün } & 15.09 .2020 \\
\cline { 2 - 2 } & 24.09 .2020 \\
\hline \multirow{2}{*}{ gün } & 07.10 .2020 \\
\cline { 2 - 2 } & 09.10 .2020 \\
\hline \multirow{2}{*}{$\mathbf{8}$ gün } & 15.10 .2020 \\
\cline { 2 - 2 } & 23.10 .2020 \\
\hline \multirow{2}{*}{$\mathbf{7}$ gün } & 22.12 .2020 \\
\cline { 2 - 2 } & 29.12 .2020 \\
\hline \multirow{2}{*}{$\mathbf{1 8}$ gün } & 11.01 .2021 \\
\cline { 2 - 2 } & 29.01 .2021 \\
\hline
\end{tabular}

Özetle, Altın (XAU) fiyatlarında 2020 yılı ortasından bu yana herhangi bir fiyat baloncuğu oluşmadığı, Brent Petrol (XBR) ve GameStop Corp (GME) hisse senedi fiyatlarında 2021 yılı başında fiyat baloncuğu oluştuğu ancak sona erdiği anlaşılmıştır. 02.01.2020-27.10.2021 tarihleri arasındaki analiz dönemi itibarıyla ilgili finansal varlık fiyatlarından yaşanan fiyat baloncuklarının toplam süresi Brent Petrol (XBR), Altın (XAU) ve GameStop Corp (GME) fiyat serilerinde sırasıyla 67 gün, 21 gün ve 56 gün olmuştur. Söz konusu fiyat baloncuğu toplam süreleri her bir finansal varlık için kullanılan gözlem sayılarına oranlandığında Brent Petrol (XBR) için 67/504=0,1329, Altın (XAU) için 21/475=0,0442 ve GameStop Corp (GME) için 56/460=0,1217 bulunmuştur. Buna göre, özellikle Brent Petrol (XBR) fiyatlarında oynaklığın (volatilite) yüksek olduğu ve spekülatif piyasa özelliği gösterdiği anlaşıldığından, politika yapıcıların ve petrole dayalı finansal varlıklara fon aktaran yatırımcıların piyasayı dikkatle takip etmesi gerektiği söylenebilir.

\section{SONUÇ VE ÖNERILER}

Spekülatif hareketler nedeniyle varlık fiyatları büyük dalgalanmalar gösterebilmektedir. Buradan hareketle çalışmada, ekonomik göstergeler üzerinde önemli etkiye sahip olan ve son dönemde üzerlerinde çokça durulan çeşitli varlıklarda yaşanan fiyat dalgalanmalarının baloncuk etkisi oluşturup oluşturmadığı Phillips, Shi ve Yu (2015) tarafından geliștirilen özyinelemeli bir Sağ Kuyruklu (Right Tailed) Genelleştirilmiş Supremum Artırılmış Dickey Fuller Testi (GSADF) tahminlenerek incelenmiştir. 
Çalışmada 02.01.2020-05.03.2021 tarihleri arasındaki USD bazlı olarak Brent ham petrol (XBR), Altın (XAU) ve Game Stop Corp (GME) hisse senedi günlük kapanış fiyatları kullanılmıştır. Elde edilen ampirik bulgular Brent Petrol (XBR), Altın (XAU) ve GameStop Corp (GME) hisse senedi fiyatlarında çok sayıda fiyat baloncuğu olduğunu göstermiştir. Altın (XAU) fiyatlarında sadece 21.07.202011.08.2020 döneminde fiyat baloncuğu olduğu tespit edilmiştir. Analiz dönemi itibarıyla Brent Petrol (XBR) fiyatlarında özellikle her yıl Mart ayında bir fiyat baloncuğu oluştuğu gözlenmiştir. Ayrıca Brent Petrol (XBR) fiyatlarında oynaklığın (volatilite) yüksek olduğu ve spekülatif piyasa özelliği gösterdiği anlaşıldığından, politika yapıcıların ve petrole dayalı finansal varlıklara fon aktaran yatırımcların piyasayı dikkatle takip etmesi gerekmektedir. GameStop Corp (GME) hisse senedi fiyatlarında Ocak 2021 itibarıyla yaşanan spekülatif fiyat baloncuğunun en uzun süren ve en şiddetlisi olduğu anlaşılmıştır. Analize konu edilen varlık fiyatlarında oluşan fiyat baloncukları için ortak bir tarih ve/veya tarih aralığı söz konusu değildir.

Fiyat baloncukları, yatırımcıların "sürü psikolojisi" temelinde yeni alıcılar da eklenerek kendi kendini besleyen (self-sustaining) bir döngü oluşturmaktadır. Analiz dönemi itibarıyla görülen fiyat baloncukları nedeniyle, söz konusu varlık fiyatlarının spekülatif hareketlere duyarlı olduğu söylenebilir.

Elde edilen sonuçlar yatırımcılar açısından spekülatif kazançlar için fırsatlar bulunduğunu göstermektedir. Bununla birlikte, anormal getiriler söz konusu olmasına karşın yatırımcılar, baloncukların patlaması durumunda olası kayıplara da hazırlıklı olmalıdırlar. Nitekim fiyat baloncuklarının ilk aşamasında birçok yatırımcı fiyat yükselişlerini normal karşılar ve balon oluştuğunu fark etmez. Bu yüzden fiyat baloncuklarının varlı̆̆ı, genellikle baloncuk patlayıp varlık fiyatları düştükten sonra anlaşılırlar.

Varlık fiyatlarındaki spekülatif baloncukların olumsuz makroekonomik etkilerini önleyebilmek üzere uygun parasal ve makro ihtiyati politikalar yürütülmelidir. Söz konusu politikalar sadece baloncuk patladıktan sonraki süreci iyileştirme amaçlı değil, aynı zamanda spekülatif fiyat baloncuklarının oluşumunu önleyici nitelikte olmalıdır.

İleride yapılacak çalışmalarda çeşitli finansal varlıklar için fiyat baloncuklarının oluşumunda rolü olan değişkenlerin araştırılması önem arz etmektedir. Nitekim gerçekleşmiş fiyat baloncuklarının başlangıç ve bitiş tarihleri itibarıyla ulusal ve uluslararası piyasalarda makroekonomik görünümün detaylı incelenmesi, potansiyel fiyat baloncuklarını önlemek adına uygun makroekonomik politikaların belirlenmesine de katkı sağlayacaktır. 


\section{KAYNAKÇA}

Abioğlu, V. (2020). Türkiye Konut Piyasasında Balon Oluşumları: Bölgesel İnceleme. Finansal Araştırmalar ve Çalışmalar Dergisi, 12(22), 1-14.

Afşar, A. and Doğan, E. (2018). Analyzing Asset of Bubbles in the Housing Market with Right-tailed Unit Root Tests: The Case of Turkey. Journal of Business Economics and Finance, 7(2), 139-147.

Ahmed, E., Rosser, JR., J. B. and Uppal, J.Y. (2016). Financialization and Speculative Bubbles International Evidence. CAMA Working Paper No. 6/2017, 1-28.

Akkaya, M. (2018). Borsa İstanbul Hisse Senedi Getirilerinde Balon Oluşumu Üzerine Bir Uygulama. C.Ü. Íktisadi ve İdari Bilimler Dergisi, 19(1), 188-200.

Bettendorf, T. and Chen W. (2013). Are There Bubbles in the Sterling-Dollar Exchange Rate? New Evidence from Sequential ADF Tests. Economics Letters, 120(2), 350-353.

Bouri, E., Shahzad, S.J.H. and Roubaud, D. (2018). Co-explosivity in the Cryptocurrency Market. Finance Research Letters. 29, 178-183.

Büyükduman, A. (2014). Bir Kent Efsanesi Konut Balonu. İstanbul: Scala Yayıncılık.

Caspı, I. (2013). Rtadf : Testing for Bubbles with EViews. Munich Personal RePEc Archive 58791, 1-16.

Ceylan F., Ekinci R., Tüzün O. ve Kahyaoğlu H. (2018). Kripto Para Piyasasında Balonların Tespiti: Bitcoin ve Etherium Örneği. Bussines ve Management Studies: An International Journal. 6(3), 263-274.

Cheung, A. Roca, E. and Su, J. (2015). Crypto-Currency Bubbles: an Application of the Phillips-Shi Yu (2013) Methodology on Mt. Gox Bitcoin Prices. Applied Economics, 47(23), 2348-2358.

Corbet, S., Lucey, B. and Yarovaya, L., (2018). Datestamping the Bitcoin and Ethereum Bubbles. Finance Research Letters, 26, 81-88.

Coşkun, Y. and Jadevicius, A. (2017). Is There a Housing Bubble in Turkey?. Real Estate Management and Valuation, 25(1), 48-73.

Çelik, İ., Akkuş, H. T. ve Gülcan, N. (2019). Investigation of Ratiınal Bubbles and Volatility Spillovers in Commodity Markets: Evidences from Precious Metals. Mehmet Akif Ersoy Üniversitesi, İktisadi ve İdari Bilimler Fakültesi Dergisi, 6(3), 937-951.

Diba, B. T. and Grossman, H. I. (1988). Explosive Rational Bubbles in Stock Prices?. American Economic Review, 78(3), 520-530.

Engsted, T., Hviid, S. J. and Pedersen, T. Q. (2016). Explosive Bubbles in House Prices? Evidence from the OECD Countries. Journal of International Financial Markets, Institutions and Money, 40, 1425.

Enoksen, F. A., Landsnes, CH. J., Lučivjanská, K. and Molnár, P. (2020). Understanding Risk of Bubbles in Cryptocurrencies, Journal of Economic Behavior \& Organization, 176, 129-144.

Escobari, D. and Jafarinejad, M. (2016). Date stamping bubbles in real estate investment trusts. The Quarterly Review of Economics and Finance, 60, 224-230.

Çağlı, E. Ç. ve Evrim Mandacı, P. (2018). Türkiye Konut Piyasasında Balon Var mı? İstatistiki Bölge Birimleri Üzerine Bir Analiz. Finans Politik ve Ekonomik Yorumlar Dergisi, 55(646), 85-113.

Ghosh, B. (2016). Rational Bubble Testing: An in-depth Study on CNX Nifty. Asian Journal of Research in Banking and Finance, 6(6), 10-16. 
Gökçe, A. ve Güler, İ. (2020). Sağ-Yönlü ADF Sınamaları ile Ankara İlinde Konut Balonu Araştırması. Ankara Hacı Bayram Veli Üniversitesi Íktisadi ve İdari Bilimler Fakültesi Dergisi, Özel Sayı, 94116.

Gülcan, N., Boyacıoğlu, N. ve Özdemir, A. (2021). Investıgation of Speculative Bubbles in Financial Markets: The Example of Foreign Exchange Market. Süleyman Demirel University Visionary Journal, 12(29 176-187.

Hepkorucu, A. ve Genç, S. (2019). Kripto Para Değerleri için Spekülatif Fiyat Balonlarının Test Edilmesi: Bitcoin Üzerine Bir Uygulama. Veri Bilimi Dergisi, 2(1), 44-50.

Hu, Y. and Oxley L. (2017). Are There Bubbles in Exchange Rates? Some New Evidence from G10 and Emerging Markets Countries. Economic Modelling, 64(C), 419-442.

$\mathrm{Hu}$, Y. and Oxley, L. (2018). Bubble Contagion: Evidence from Japan's Asset Price Bubble of the 198090s. Journal of the Japanese and International Economies, 50, 89-95.

İskenderoğlu, Ö. ve Akdağ, S. (2019). Türkiye’de Reel Konut Fiyatlarında Balonların Varlığı Üzerine Uygulamalı Bir Analiz. Business and Economics Research Journal, 10(5), 1085-1093.

Jiang, C., Wang, Y., Chang T. and Su, C. W. (2015). Are There Bubbles in Chinese RMB-Dollar Exchange rate? Evidence from Generalized Sup ADF Tests. Applied Economics, 47(56), 6120-6135.

Kansu, A. (2011). Konut Balonundan Finansal Krize: ABD Mortgage Krizi. İstanbul: Scala Yayıncllık.

Kılıç, Y. (2020). Finansal Piyasalarda Balon Varlığının Test Edilmesi: BRICS-T Ülkeleri Örneği. Journal of Banking and Capital Markets Research, 4(9), 11-22.

Korkmaz, Ö., Erer, D. ve Erer, E. (2016). Alternatif Yatırım Araçlarında Ortaya Çıkan Balonlar Türkiye Hisse Senedi Piyasasını Etkiliyor mu? BİST 100 Üzerine Bir Uygulama. BDDK Bankacılık ve Finansal Piyasalar Dergisi, 10(2), 29-61.

Landgraf, N. (2016). Testing for Multiple Bubbles in Asset Prices. Research in Business and Economics, $1(1), 1-24$.

Lind, H. (2009). Price Bubbles in Housing Markets: Concept, Theory and Indicators. International Journal of Housing Markets and Analysis, 2(1), 78-90.

Mete, S., Koy, A. ve Ersoy, H. (2019). Kriptoparalarda Fiyat Balonu İncelemesi. BDDK Bankacılık ve Finansal Piyasalar Dergisi, 13(1), 105-120.

Pavlidis, E. G., Paya I. and Peel D. (2017). Testing for Speculative Bubbles Using Spot and Forward Prices. International Economic Review, 58(4), 1191-1226.

Phillips, P. C. B., Wu, Y. and Yu, J. (2011). Explosive Behavior in The 1990s Nasdaq: When Did Exuberance Escalate Asset Values?. International Economic Review, 52(1), pp. 201-226.

Phillips, P.C.B., Shi, S. and Yu, J. (2015). Testing for Multiple Bubbles: Historical Episodes of Exuberance and Collapse in the S\&P 500. International Economic Review, 56(4), 1043-1077.

Rasekhi, S., Elmi, Z. M. and Shahrazi M. (2017). Testing for Multiple Bubbles in Iranian Foreign Exchange Market: The Application of RTADF Unit Root Tests. The Journal of Economic Modeling Research, 7 (27), 7-39.

Shi, S., Valadkhani, A., Smyth, R. and Vahid, F. (2016). Dating the timeline of house price bubbles in Australian capital cities. Economic Record, 92(299), 590-605.

Su, C. W., Li, Z. Z., Tao, R. and Si, D. K. (2018). Testing for Multiple Bubbles in Bitcoin Markets: A Generalized sup ADF test. Japan and the World Economy, 46(C), 56-63. 
Şahin, E. E. (2020). Kripto Para Fiyatlarında Balon Varlığının Tespiti: Bitcoin, IOTA ve Ripple Örneği. Selçuk Üniversitesi Sosyal Bilimler Enstitüsü Dergisi, 43, 62-69.

Wei, D. (2017). Price Bubbles in Bitcoin: Evidence, Causes and Implications, Journal of Shanghai University of Finance and Economics, 19(2), 50-62.

Zeren, F. and Ergüzel, O. S. (2015). Testing for Bubbles in the Housing Market: Further Evidence from Turkey. Financial Studies, 19(1), 40-52.

Zeren, F. ve Esen, S. (2018). Geleceğin Para Birimi ya da Sadece Bir Balon: Bitcoin. Balıkesir Üniversitesi Sosyal Bilimler Enstitüsü Dergisi, 21(39), 433-444. 


\section{EXTENDED ABSTRACT}

\section{Analysis of Speculative Price Bubbles in Asset Prices Using the Right-Tailed ADF Method}

\section{Introduction}

The bubbles caused by excessive price inflation in financial asset prices and the bursting of these bubbles in the future threaten the economic stability. Therefore, investigating the bubble behavior in asset prices and their frequency over time is of great importance in terms of global economic stability, especially in emerging markets. Rapid and continuous increases in asset prices suggest that there is a price bubble that is not considered rational. A price bubble is expressed as the situation in which the actual value in the market increases rapidly and diverges from the fundamental value.

The main purpose of this study is to investigate price bubbles in various asset prices, which have a significant impact on economic indicators and have been frequently emphasized recently. In this context, the paper aims to investigate the presence of price bubbles in Brent crude oil (XBR) as commodity, Gold (XAU) as precious metal and GameStop Corp. (GME) as stock prices with GSADF tests, as well as to determine datestamps of the price bubbles. The contribution of the study to the literature is that, in addition to the crude oil and gold prices, which are carefully followed in the global markets and which seriously affect the economic indicators, the GameStop Corp stock prices, which have not yet been researched on price bubbles, have been analyzed.

\section{Data Set and Method}

Daily closing prices of Brent crude oil (XBR), Gold (XAU) and Game Stop Corp (GME) stocks on USD basis between 02.01.2020-27.10.2021 were used in the study. The data is taken from the investing.com database.

In the study, the existence and development periods of price bubbles were determined by estimating a recursive Right Tailed Generalized Supremum Augmented Dickey Fuller Test (GSADF) developed by Phillips, Shi and Yu (2015). The recursive GSADF test, allows the examination of multiple price bubble structures over the entire time series. The GSADF method has a datestamping strategy that captures both the existence of price bubbles and the beginning and ending points of a bubble.

In the GSADF test, the starting point in the sample is not fixed, but shifted over the starting and ending points. Thus, it becomes possible to detect multiple bubbles with the GSADF test. The GSADF also takes into account nonlinear structures and structural breaks. If the calculated GSADF test statistics are greater than the critical values which calculated as a result of Monte Carlo simulations, the null hypothesis claiming that there are no financial bubbles is rejected. The rejection of the null hypothesis indicates the existence of rational bubbles in price series. After detecting the presence of bubbles, the formation periods of the bubbles are determined using retrospective SADF (Backwards sup ADF - BSADF) statistics series. BSADF statistical sequences are obtained using right-tailed ADF tests for samples of a backward expanding structure.

\section{Empirical Findings}

In line with the empirical findings obtained, it has been determined that there is a price bubble in Gold (XAU) prices only in the period of 21.07.2020-11.08.2020. As of the analysis period, a price bubble has been observed in Brent Oil (XBR) prices, especially in March every year. The interesting point here is regarding GameStop Corp (GME) stock prices. As a matter of fact, it has been determined that a historical manipulation movement was accepted in GameStop Corp (GME) stock prices, not only in January 2021, but also in September, October and December 2020 before, price bubbles were formed. It has been understood that the speculative price bubble in GameStop Corp (GME) stock prices as of January 2021 is the longest and most severe. There is no common date and/or date range for the price bubbles in the asset prices subject to the analysis. 
As of the analysis period between 02.01 .2020 and 27.10.2021, the total duration of the price bubbles in the prices of the relevant financial assets was 67 days, 21 days and 56 days, respectively, in the Brent Oil (XBR), Gold (XAU) and GameStop Corp (GME) price series. When the total duration of the aforementioned price bubble is compared to the number of observations used for each financial asset, $67 / 504=0.1329$ for Brent Oil (XBR), 21/475 $=0.0442$ for Gold (XAU), and 56/460 $=0.1217$ for GameStop Corp (GME). Accordingly, it can be said that policy makers and investors who transfer funds to oil-based financial assets should follow the market carefully, especially since it is understood that the volatility in Brent Oil (XBR) prices is high and shows a speculative market characteristic.

\section{Discussion and Conclusion}

Since it is understood in the study that the volatility of Brent Oil (XBR) prices is high and shows speculative market characteristics, policy makers and investors transferring funds to oil-based financial assets should follow the market carefully. It has been understood that the speculative price bubble in GameStop Corp (GME) stock prices as of January 2021 is the longest and most severe. There is no common date and/or date range for the price bubbles in the asset prices subject to the analysis.

The results show that there are opportunities for speculative gains for investors. However, even though there are abnormal returns, investors should also be prepared for possible losses if the bubbles burst. As a matter of fact, in the first stage of price bubbles, many investors consider price increases as normal and do not realize that bubbles are formed. Therefore, the existence of price bubbles is usually discovered after the bubble bursts and asset prices fall.

Appropriate monetary and macroprudential policies should be implemented in order to prevent the negative macroeconomic effects of speculative bubbles in asset prices. These policies should not only aim to improve the process after the bubble burst, but also prevent the formation of speculative price bubbles.

In future studies, it is important to investigate the variables that play a role in the formation of price bubbles for various financial assets. As a matter of fact, a detailed examination of the macroeconomic outlook in national and international markets as of the start and end dates of realized price bubbles will also contribute to the determination of appropriate macroeconomic policies in order to prevent potential price bubbles. 